\title{
Uniform distribution of satellite DNA variants on the chromosomes of tenebrionid species Alphitobius diaperinus and Tenebrio molitor
}

\author{
BRANKA BRUVO, MIROSLAV PLOHL and ĐURDICA UGARKOVIĆ \\ Department of Molecular Genetics, Ruđer Bošković Institute, Zagreb, Croatia
}

\begin{abstract}
Bruvo, B., Plohl, M. and UGarković, Đ. 1995. Uniform distribution of satellite DNA variants on the chromosomes of tenebrionid species Alphitobius diaperinus and Tenebrio molitor. - Hereditas 123: 69-75. Lund, Sweden. ISSN 0018-0661. Received June 9, 1995. Accepted September 7, 1995

The chromosomes of tenebrionid species Alphitobius diaperinus contain large blocks of pericentromerically located constitutive heterochromatin, as revealed by C-banding procedure. As previously reported, satellite DNA of this species is composed of two related monomeric units organized in three satellite subfamilies. In order to analyze the chromosomal location of the satellite DNA and the distribution of monomeric variants within it, and compare it with the distribution of monomer variants in Tenebrio molitor satellite DNA, the methods of in situ hybridization and restriction enzyme/nick translation were performed. Fluorescent in situ hybridization with the entire satellite DNA reveals the pericentromerically located signals on all chromosomes of the complement, coinciding with heterochromatic blocks. Results of fluorescent in situ hybridization with particular monomeric variants and of in situ restriction enzyme/nick translation show that monomeric variants are homogeneously dispersed within the entire satellite DNA. The spreading of satellite monomeric variants of the related species $T$. molitor within the pericentromeric heterochromatin of the entire complement, is demonstrated using the method of in situ restriction enzyme/nick translation. Although the complexity of organization of satellite DNAs is quite distinct in these two species, obtained results suggest similar efficiency of mechanisms of spreading and homogenization resulting in random chromosomal distribution of their satellite variants.
\end{abstract}

Durdica Ugarković, Department of Molecular Genetics, Ruđer Bošković Institute, P.O. Box 1016, Bijenička 54, 41000 Zagreb, Croatia

Tandemly arranged highly repetitive DNA sequences or satellite DNAs are found in genomes of all higher eukaryotes and often comprise considerable portion of genomic DNA. Satellite DNAs are usually species-specific and can diverge significantly among related species. Despite their usual transcriptional inactivity and absence of coding functions, several possible roles are proposed for satellite DNAs, originating from their frequent connection with centromeric and telomeric regions of eukaryotic chromosomes (MIKLOS 1985; JOHN 1988; IRICK 1994).

Insect species belonging to the family Tenebrionidae (Coleoptera) have abundant satellite DNAs, which can build up to $50 \%$ of the total genome, as in the case of Tenebrio molitor (PETITPIER RE et al. 1988). In species of this family analyzed so far, satellite DNAs are located in large blocks of constitutive heterochromatin in pericentromeric regions of all chromosomes (DAVIS and WYATT 1989; PloHl et al. 1993; JuAN et al. 1993a; PONS et al. 1993; PLOHL and UGARKović 1994a). Only in few cases can the satellite DNAs also be detected in telomeric regions of some chromosomes of the complement (JUAN et al. 1993b; UGARKović et al. 1994). Tenebrio molitor is so far the best characterized representative from this insect family, at the molecular as well as at the cytogenetical level. Its satellite DNA is composed of tandemly arranged, highly conserved $142 \mathrm{bp}$ long monomeric units (PeTITPIERRE et al. 1988; DAVIS and WYATT 1989; UGARKOVIĆ et al. 1989). Monomer sequence variants, which are products of single base substitutions, are randomly distributed within the whole satellite DNA (PLOHL et al. 1992). Quite opposite to this simple organization, it was found that the satellite DNA of the species Alphitobius diaperinus is constituted of two related monomeric variants, dS1 and dS2 (123 and $126 \mathrm{bp}$, respectively), having $65.9 \%$ average sequence homology. They are organized in repeating structures of higher order: dimer dS1-dS2 and trimer dS1$\mathrm{dS} 2-\mathrm{dS} 2$, which furthermore create three satellite subfamilies (Plohl and Ugarković 1994b).

In this paper we report the chromosomal position of $A$, diaperinus satellite DNA as determined by fluorescent in situ hybridization (FISH); methods of in situ restriction enzyme/nick translation 

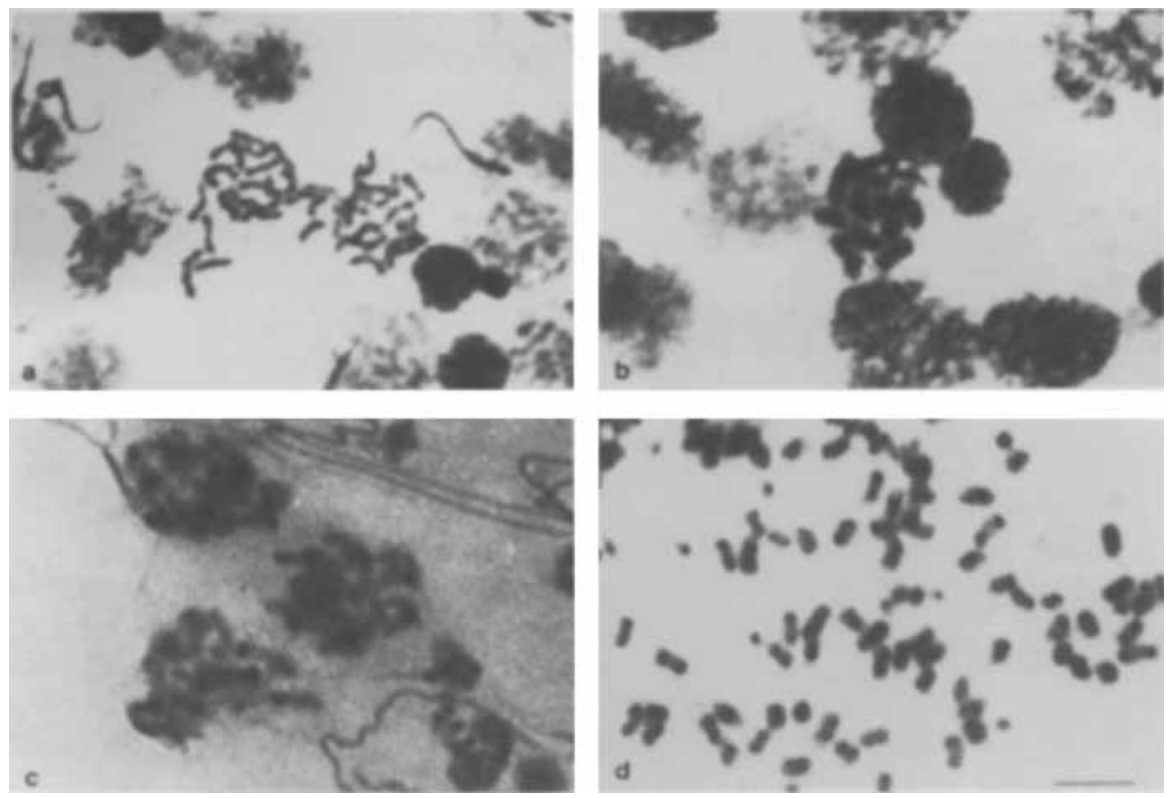

Fig. 1a-d. Chromosomes of Alphitobius diaperinus stained with Giemsa, in mitotic metaphase (a), and meiotic metaphase I (b). C-banding of A. diaperinus chromosome bivalents in the phases of pachytene (c) and meiotic metaphase I (d), with darkly stained heterochromatic regions. $\operatorname{Bar}=5 \mu \mathrm{m}$.

(ISRE/NT) as well as FISH were used to determine the distribution and organization of particular monomeric units on the chromosomes of $A$. diaperinus. With the ISRE/NT we also defined the chromosomal arrangement of monomer sequence variants of the $T$. molitor satellite and compared obtained cytogenetical results with molecular characterization of their organization as obtained earlier (PlOHL et al. 1992).

\section{Materials and methods}

Chromosome preparations, C-banding and DAPI staining

Meiotic and mitotic chromosome spreads were obtained from male adult or larval gonads. The tissue was fixed in ethanol-acetic acid (3:1) for $1 \mathrm{~h}$, squashed in $45 \%$ acetic acid, and frozen in liquid nitrogen. Conventional staining was performed in $4 \%$ Giemsa in phosphate buffer ( $\mathrm{pH} \mathrm{6.8)}$ for 15 min. C-banding was done according to SUMNER (1972).

Staining of the chromosomes with fluorochrome DAPI was performed with $0.2 \mu \mathrm{g} / \mathrm{ml}$ DAPI in
McIlvaine's phosphate buffer for 15 min (SUMNER 1990).

\section{Fluorescent in situ hybridization}

Chromosome preparations were pretreated with RNase A $(100 \mu \mathrm{g} / \mathrm{ml})$ in $2 \times \mathrm{SSC}$ for $1 \mathrm{~h}$ at $37^{\circ} \mathrm{C}$ and pepsin $(100 \mu \mathrm{g} / \mathrm{ml})$ in $10 \mathrm{mM} \mathrm{HCl}$ at $37^{\circ} \mathrm{C}$ for $10 \mathrm{~min}$, dehydrated in an ethanol series, and denatured at $70^{\circ} \mathrm{C}$ for $2 \mathrm{~min}$ in $70 \%$ formamide, $2 \times$ SSC. Cloned T. molitor satellite monomer, $A$. diaperinus $\mathrm{d} \mathbf{S} 2$ monomer, $\mathrm{d} \mathbf{S} 1-\mathrm{d} S 2$ dimer, and $\mathrm{d} S 1$ dS2-dS2 trimer were labelled with biotin-16-dUTP (Gibco BRL) by nick translation. Hybridization was performed at $37^{\circ} \mathrm{C}$ overnight in a mixture which contained $10 \mathrm{ng} / \mu 1$ of labelled probe, $60 \%$ formamide, $1.6 \times \mathrm{SSC}, 8 \%$ dextran-sulfate, and $20 \mathrm{mM}$ Na-phosphate. The hybridization probes for $A$. diaperinus chromosomes were the following: (1) the mixture of labelled dimer and trimer; (2) labelled dS2 monomeric unit; (3) labelled dimer with the addition of unlabelled monomeric dS2 unit in ten-fold concentration. Slides were washed $3 \times 5 \mathrm{~min}$ in $50 \%$ formamide, $2 \times \mathrm{SSC}$ at $37^{\circ} \mathrm{C}$. Immunological detection was achieved using the avidin-FITC system with amplification (PINKEL 

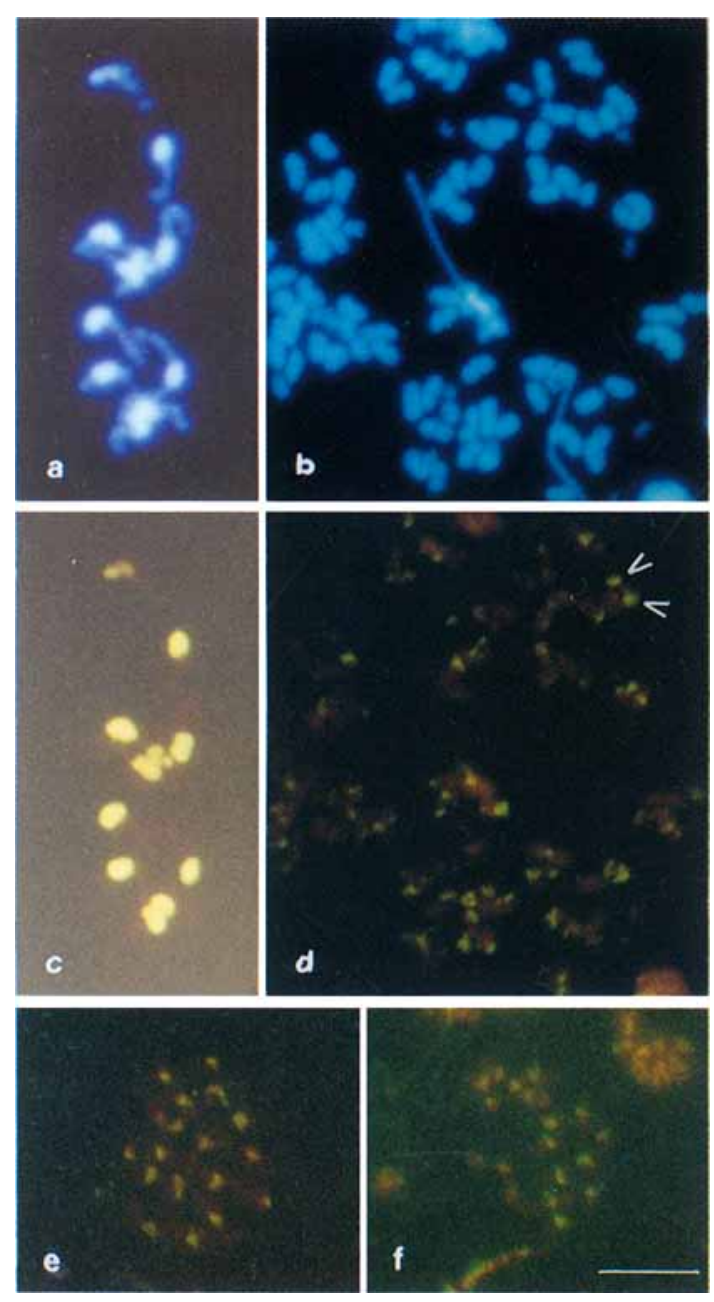

Fig. 2a-f. DAPI staining of Tenebrio molitor pachytene chromosomes (a) and $A$, diaperinus meiotic metaphase I chromosomes (b). FISH of $T$. molitor (c) and $A$. diaperinus ( $\mathbf{d}, \mathbf{e}, \mathbf{f})$ chromosomes with cloned satellites from each species. Mitotic prometaphase (e) and metaphase (f) chromosomes are hybridized with the cloned dS2 monomeric unit. For meiotic metaphase I chromosomes in (d) the mixture of cloned dS1-dS2 dimer and dS1-dS2$\mathrm{dS} 2$ trimer is used as a hybridization probe. Chromosomes in (c), (d), (e), and (f) are counterstained with propidium-iodide, and yellow FITC regions correspond to hybridization signals. Arrowheads in (d) depict positions of centromeres on one of the bivalents. Bar $=10 \mu \mathrm{m}$ in (a), (c), and $5 \mu \mathrm{m}$ in (b), (d), (e), (f).

et al. 1986). The chromosomes were counterstained with propidium-iodide and photographed in a Zeiss Axiophot microscope using the appropriate filters for fluorescence.

\section{In situ RE/nick translation}

Chromosome preparations were incubated at $37^{\circ} \mathrm{C}$ for $30 \mathrm{~min}$ with $50 \mathrm{U}$ of BamHI, KpnI, AvaI or $B g l \mathrm{II}$, or with $20 \mathrm{U}$ of $\mathrm{HpaI}$, in a total volume of $50 \mu \mathrm{l}$. The nick translation procedure was performed according to DE LA TORRE et al. (1991). Immunological detection of incorporated biotin16-dUTP was as in the in situ hybridization procedure.

\section{Results}

\section{Giemsa staining and C-banding}

The males of Alphitobius diaperinus have a chromosome number of $2 \mathrm{n}=19(18+\mathrm{X})$, chromosomes are very small, approximately $1-3 \mu \mathrm{m}$ in mitotic metaphase and are mainly meta- or submetacentric. Conventional Giemsa staining procedure gives uniform staining along the mitotic and meiotic chromosomes (Fig. la and 1b), while Cbanding of pachytene and meiotic metaphase bivalents results in large positive heterochromatic bands, located in pericentromeric regions of all chromosomes (Fig. 1c and 1d). The presence of large blocks of constitutive heterochromatin, located pericentromerically on all chromosomes of Tenebrio molitor and several other related species, has been previously reported (WEITH 1985; JUAN and Petitpierre 1989).

\section{DAPI staining and fluorescent in situ hybridization}

Spermatogonial meiotic chromosomes of $T$. molitor and $A$. diaperinus were stained with fluorochrome DAPI, which binds to A-T rich DNA and induces more intense fluorescence of such regions. Fig. 2a shows pachytene chromosomes of $T$. molitor, with bright pericentromeric regions corresponding to heterochromatic blocks. The A-T content of $58.5 \%$ of this satellite DNA (PETrTPIERRE et al. 1988; DAVIS and WYATT 1989; UGARKOVIĆ et al. 1989) enhances the intensity of DAPI binding in the pericentromeric areas.

Satellite DNA of $A$. diaperinus is composed of $50.8 \% \mathrm{G}-\mathrm{C}$ base pairs (PLOHL and UGARKović 1994b). Therefore, similar G-C and A-T content gives rise to uniform DAPI staining of whole chromosomes in meiotic metaphase I (Fig. 2b), making a distinction impossible between heterochromatic and euchromatic areas.

Preparations of $T$. molitor and $A$. diaperinus chromosomes were hybridized with biotinylated, 

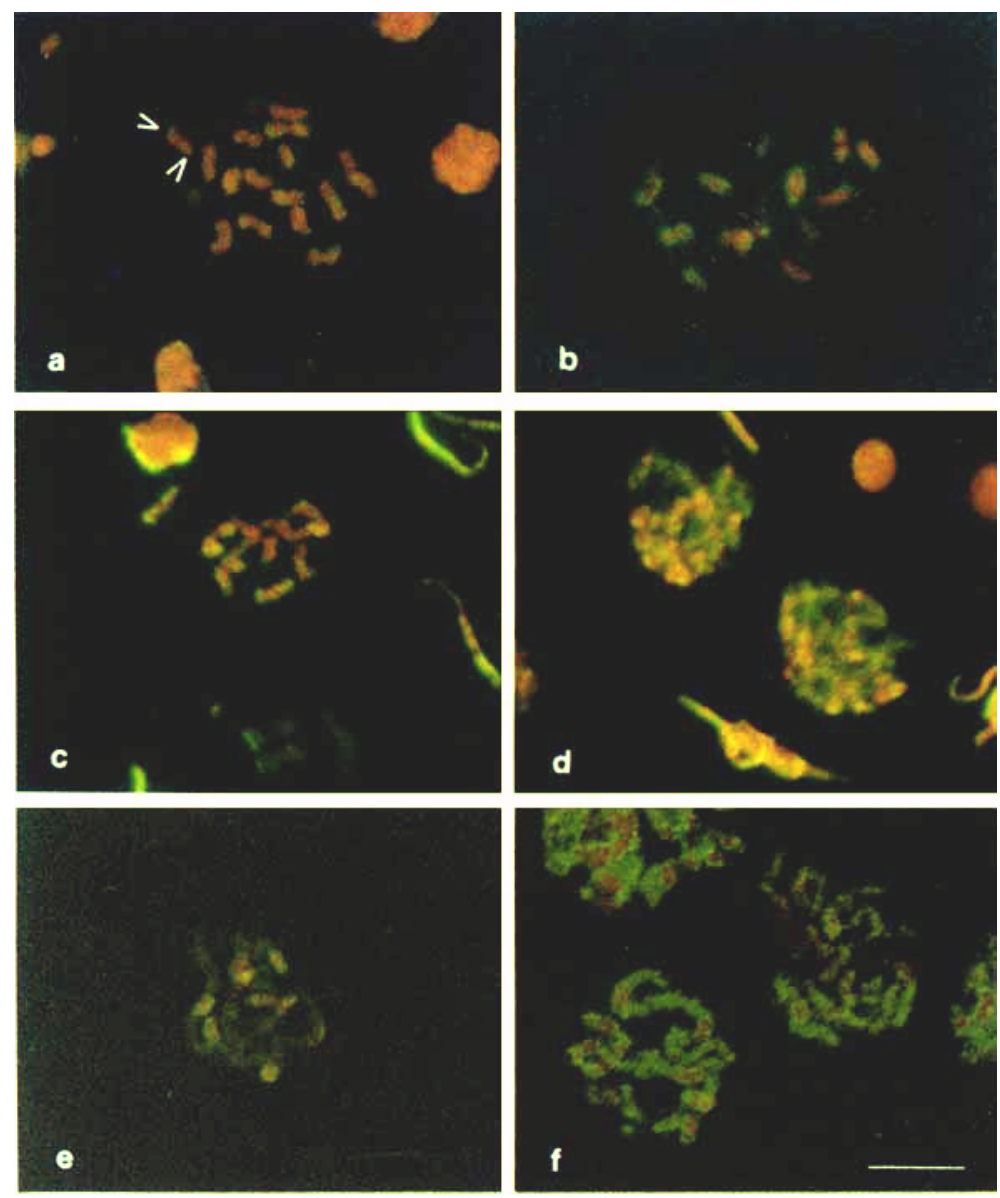

Fig. 3a-f. ISRE/NT of Alphitobius diaperinus meiotic chromosomes (a-d). Nicks on the chromosomes were induced with REs BglII in (a), (b), and with AvaI in (c), (d). Chromosomes are in meiotic metaphase $\mathrm{I}$ in the figures (a), (b), (c) and in meiotic prometaphase in (d). Arrowheads in (a) depict positions of centromeres on one of the bivalents. ISRE/NT of Tenebrio molitor pachytene bivalents after inducing nicks on the chromosomes with REs HpaI (e) and $\operatorname{Bam} \mathrm{HI}(\mathbf{f})$. Chromosomes are counterstained with propidium-iodide, while the regions with incorporated biotin-labelled nucleotides appear as bright FITC-signals. Bar $=5 \mu \mathrm{m}$ in (a), (b), (c), (d), and $10 \mu \mathrm{m}$ in (e), (f).

cloned satellite probes of the respective species. Results of FISH obtained on T. molitor chromosomes are in accordance with published data (DAVIS and WYATt 1989; JUAN et al. 1993b), showing the localization of satellite DNA in the pericentromeric regions of all 20 chromosomes (Fig. 2c). Fig. 2d shows meiotic metaphase bivalents of $A$. diaperinus hybridized with a probe constituted of the mixture of the cloned satellite $\mathrm{dS} 1-\mathrm{dS} 2$ dimer and $\mathrm{dS} 1-\mathrm{dS} 2-\mathrm{dS} 2$ trimer. Hybridization signals are positioned in centromeric areas, and coincide with regions of constitutive heterochromatin on all chromosomes of the complement.
In order to check the distribution and chromosomal organization of $A$. diaperinus satellite variants $\mathrm{dS} 1$ and $\mathrm{dS} 2$, we performed FISH with cloned dS2 unit and separately with cloned dimeric unit $(\mathrm{dS} 1-\mathrm{dS} 2)$ in the presence of huge excess of unlabelled dS2. Fig. 2e and $2 \mathrm{f}$ show mitotic prometaphase and metaphase chromosomes of $A$. diaperinus hybridized with the $\mathrm{d} S 2$ variant. Hybridization signals are positioned in pericentromeric areas of all 19 chromosomes, indicating the uniform distribution of the dS2 unit within the whole satellite-DNA. Hybridization with labelled dimer blocked with $\mathrm{d} S 2$ monomeric unit reveals the distribution of $\mathrm{dS} 1$ identical to that of $\mathrm{dS} 2$, in peri- 
centromeric regions of all chromosomes (results not shown).

\section{In situ $\mathbf{R E}$ /nick translation}

ISRE/NT was used as additional method for determination of monomer variant distribution within the satellite DNA. For inducing nicks on the chromosomes of $A$. diaperinus, REs AvaI, which recognizes only dS2 unit, and $B g / \mathrm{II}$, which preferentially cuts in dS1, were used. These two REs have a single restriction site in the particular monomeric unit.

Fig. $3 \mathrm{a}$ and $3 \mathrm{~b}$ show meiotic metaphase bivalents of $A$. diaperinus after $B g l \mathrm{II} /$ nick translation, with fluorescent signals visible along the centromeric regions of all chromosomes. Quite similar result was obtained after AvaI/nick translation (Fig. 3c and $3 \mathrm{~d}$ ), with incorporated labelled nucleotides in heterochromatic blocks of all chromosomes. Mild fluorescence visible in non-heterochromatic parts of chromosomes, originates from occasional restriction sites for these enzymes in euchromatic DNA. It can be concluded that both monomeric units $\mathrm{dS} 1$ and $\mathrm{dS} 2$ are present uniformly on all chromosomes of the $A$. diaperinus complement. Recognition sites for REs $A v a \mathrm{I}$ and $B g l \mathrm{II}$ are characteristic for all three satellite subfamilies, and so the obtained results also indicate their random and uniform distribution.

REs BamHI, KpnI, and $H p a \mathrm{I}$ were used to induce nicks on $T$. molitor chromosomes. The organization of $T$. molitor satellite DNA is much simpler than that of $A$. diaperinus. It is composed of just one type of monomeric unit, and the satellite monomer variants are defined by the existence of particular restriction sites. As previously described, $H p a \mathrm{I}$ has restriction sites in approx. $50 \%$ of satellite monomers (PLOHL et al. 1992). Such high frequency of $\mathrm{HpaI}$ recognition sites in satellite DNA, in comparison with those in euchromatic DNA, results in incorporation of biotin-labelled nucleotides mainly in the pericentromeric regions of $T$. molitor chromosomes, while in the euchromatin the fluorescent signal is much weaker (Fig. 3e). Fluorescent signals appear equally distributed in pericentromeric heterochromatin of all 20 chromosomes, which means that $\mathrm{HpaI}$ monomer variants are dispersed homogeneously within the entire satellite DNA. REs BamHI (Fig. 3f) and KpnI (data not shown) are present in a very small percentage of monomeric variants $(0.5-1 \%)$, and so the probability of their digestion is much higher in non-satellite parts of the genome. According to this, fluorescent signals are much more intense in euchromatic than in heterochromatic regions of the chromosomes. Nevertheless, the signals are present in the whole heterochromatin of all 20 chromosomes, so the distribution of $B a m \mathrm{HI}$ and $K p n \mathrm{I}$ sequence variants is comparable to that of $\mathrm{HpaI}$ variants. The results of ISNT after $H p a I, B a m H I$, and $K p n I$ digestion point to the uniform and random distribution of these variants within the entire satellite DNA. Also, they confirm the expected frequency of distribution in eu- and heterochromatin based on the results of molecular analysis of $T$. molitor satellite DNA with the same REs (PloHL et al. 1992).

\section{Discussion}

The insect family Tenebrionidae (Coleoptera) has several cytogenetical features well conserved in the sample of 200 species analyzed up to now ( $1 \%$ of all described tenebrionids), which can therefore be regarded as characteristic for this family. The diploid chromosome number of $2 n=20$ is highly conserved, although the sex-determining systems can diverge in several ways (JUAN and PETrTPIERRE 1991). Furthermore, C-banding technique showed the presence of large and compact blocks of constitutive heterochromatin, predominantly positioned pericentromerically on all chromosomes of the complement (JUAN and PETITPIERRe 1989). Our results reveal that such chromosomal organization of constitutive heterochromatin is also characteristic for $A$. diaperinus. All of 19 chromosomes appear to contain a considerable amount of positive C-banded material that occupies exclusively the pericentromeric regions of chromosomes. Similar ratio between eu- and heterochromatin was also observed for several other tenebrionid/species (WEITH 1985; JUAN and PETITPIERRE 1989).

The chromosomal localization of satellite DNA has been reported so far for several tenebrionid species. For those among them containing only one highly abundant satellite DNA, its location coincides with pericentromeric heterochromatin of all chromosomes, like in $T$. molitor (JUAN et al. 1993b), Tribolium confusum (PLOHL et al. 1993), and Tribolium freemani (JUAN et al. 1993a). This type of chromosomal distribution also proved to be the case for $A$. diaperimus, having also a single satellite DNA which is organized in three subfamilies (PLOHL and UGarković 1994b). This 
seems to be the main, although not exclusive, mode of satellite DNA distribution on the chromosomes within the family Tenebrionidae. In Tenebrio obscurus and Misolampus goudoti, which contain two different satellites, their chromosomal distribution is more complex. Besides the pericentromeric location on all chromosomes, hybridization signal of one of the satellites is also observed on subtelomeric regions on some of the homologues (JUAN et al. 1993b; Ugarković et al. 1994). Similar distribution has been observed for satellite DNAs of some other insect species (ARNOLD and SHAW 1985; VAlgeIRSDOTtiR et al. 1990; COHN and EDSTRÖM 1992).

The method of in situ RE/NT, originating from the commonly used method of DNA digestion with REs in situ, is very sensitive and useful for determining the chromosomal organization of satellite DNAs (ADOLPH 1988; DE LA TORRE et al. 1991). It could also enable the precise distinguishing among the satellite variants characterized by the presence of recognition sites for particular REs used to induce nicks on chromosomal DNA. To analyze distribution of satellite variants, we applied ISRE/NT to chromosomes of $A$. diaperinus and $T$. molitor, two related species with significant differences in organization of their satellite DNAs. $T$. molitor is a striking example of a species with highly conserved satellite DNA, composed of only one type of monomeric unit with average mutation rate of only $1.8 \%$ (UGARKOvIĆ et al. 1989). Satellite DNA of $A$. diaperinus is also well conserved, its average mutation rate is $3.7 \%$, but its composition of two monomeric units and organization in three satellite subfamilies makes it much more complex than that of T. molitor (PLOHL and UGARKović 1994b).

The results of ISRE/NT and FISH clearly show that the satellite monomeric variants of both species are completely randomly and uniformly distributed within the whole satellite DNA. Spreading of variants within the pericentromeric heterochromatin of the entire complement is observed and no clustering of any analyzed variant is detected. $A$. diaperinus and $T$. molitor satellite DNAs are thus, although organizationally quite distinct and diverse, very similar regarding their entire sequence homogenization and a process of intra- and interchromosomal spreading of variants within the entire chromosomal complement. It seems that the processes of spreading like gene conversion and unequal crossingover (Dover 1986) are very efficient and much faster than average mutation rate, ensuring the equivalent distribution of newly originated variants within the chromosomes and between the homologous and nonhomologous chromosomes. Similar distribution of satellite variants has been observed in species from the genus Peromyscus. Four related satellite DNAs produced the same hybridization pattern on all chromosomes, supporting the idea of their concerted evolution (HAMilton et al. 1992). Different from such random distribution, in a wide variety of higher eukaryotes satellite variants are clustered on particular chromosomes (ALTENBURGER et al. 1977; HORZ and ZACHAU 1977; WARBURTON and WILlARD 1990; HAAF et al. 1993; BorŠTNIK et al. 1994) or form chromosome-specific subsets which are described for many of the human chromosomes (CHOO et al. 1991).

The study of satellite DNA digestion in situ revealed the different factors affecting its ability to be cleaved by certain REs. It was proposed that heterochromatin conformation and satellite DNAprotein interaction could be important for the digestion pattern, which varies even between closely related species (JUAN et al. 1991; DE LA TORRE et al. 1991; UGARKović et al. 1994). In the case of $A$. diaperinus and $T$. molitor chromosomes, satellite DNA digestion in situ proceeds with the same efficiency as in naked DNA. All tested REs cleave chromosomal DNA with predicted frequency in heterochromatic as well as in euchromatic regions, and so it can be concluded that the chromatin of these two species is composed in such a manner that does not affect DNA digestion in situ, making the ISRE/NT method reliable in the analysis of these species.

Acknowledgement. - This work was supported by the Research Fund of Republic of Croatia, project no. 1-08-269.

\section{References}

AdolPH, S. 1988. In situ nick translation distinguishes between C-band positive regions on mouse chromosomes. - Chromosoma 96: $102-106$

Altenburger, W., Horz, W. and Zachau, H. G. 1977. Comparative analysis of three guinea pig satellite DNAs by restriction nucleases. - Eur. J. Biochem. 73; 393-400

ARNOLD, M. L. and SHAW, D. D. 1985. The heterochromatin of grasshoppers from the Caledia captiva species complex.Chromosoma 93: 183-190

Borštnik, B., Pumpernik, D., lukman, D., Ugarković, D. and PLOHL M. 1994. Tandemly repeated pentanucleotides in DNA sequences of eucaryotes. - Nucleic Acids Res. 22: 34123417

Choo, K. H., Vissel, B., Nagr, A. and Kalitsis, P. 1991. A survey of the genomic distribution of alpha satellite DNA on all human chromosomes and derivation of a new consensus sequence. - Nucleic Acids Res. 19: 1179-1182 
Conn, M. and Edström, J. E. 1992. Chromosome ends in Chironomus pallidivittatus contain different subfamilies of telomere-associated repeats. - Chromosoma 101: 634-640

DAvis, C. A. and WyATt, G. R. 1989. Distribution and sequence homogeneity of an abundant satellite DNA in the beetle, Tenebrio molitor. - Nucleic Acids Res. 17: 5579-5586

de la Torre, J., Mitchell, A. R. and Sumner, A. T. 1991 Restriction endonuclease/nick translation of fixed mouse chromosomes: A study of factors affecting digestion of chromosomal DNA in situ. - Chromosoma 100: 203-211

Dover, G. A. 1986. Molecular drive in multigene families: how biological novelties arise, spread and are assimilated. - Trends in Genet. 168: 159-165

HaAf, T., Schmid, M., Sternlein, C., Galettr, P. M., Jr, and WILLARD, H. F. 1993. Organization and molecular cytogenetics of a satellite DNA family from Hoplias malabaricus (Pisces, Erythrinidae). - Chromosome Res. 1: 77-86

Hamilton, M. J., HonG, G. and WichmaN, H. A. 1992. Intragenomic movement and concerted evolution of satellite DNA in Peromyscus: evidence from in situ hybridization. - Cytogenet. Cell Genet. 60: 40-44

HoRz, W. and ZACHAU, H. G. 1977. Characterization of distinct segments in mouse satellite DNA by restriction nucleases. - Eur. J. Biochem. 73: 383-392

IRICK, H. 1994. A new function for heterochromatin. - Chromosoma 103: 1-3

JOHN, B. 1988. The biology of heterochromatin. - In: Heterochromatin. Molecular and Structural Aspects, (ed. R. S. VERMA), Cambridge University Press, Cambridge, Mass., p. 1-147

JuAN, C. and PetitPierRe, E. 1989. C-banding and DNA content in seven species of Tenebrionidae (Coleoptera). - Genome 32: $834-839$

Juan, C. and Petitpierre, E. 1991. Chromosome numbers and sex-determining systems in Tenebrionidae (Coleoptera). - In: Advances in Coleopterology. (eds $M$. ZuNINO X. BELLES and $\mathrm{M}$ BLAS), AEC Barcelona, p. 167-176

Juan, C., Gosalvez, J., Mezzanotte, R. and Petitpierre, E. 1991. Cytological and biochemical characterization of the in situ endonuclease digestion of fixed Tenebrio molitor chromosomes. - Chromosoma 100: 432-438

Juan, C., Vazquez, P., Rubio, J. M., Petitpierre, E. and HewitT, G. M. 1993a. Presence of highly repetitive DNA sequences in Tribolium flour beetles. - Heredity 70: 1-8

Juan, C., Pons, J. and PetitPierre, E. 1993b. Localization of tandemly repeated DNA sequences in beetle chromosomes by fluorescent in situ hybridization. - Chromosome Res. 1: 167174

MıK Los, G. L. G. 1985. Localized highly repetitive DNA sequences in vertebrate and invertebrate genomes. - In: Molecular Evolutionary Genetics, (ed. R. J. Macintrre), Plenum Press, New York, p. 241-321
Petitpierre, E., Gatewood, J. M. and Schmid, C. W. 1988. Satellite DNA from the beetle Tenebrio molitor. - Experientia 44: 498-499

Pinkel, D., Gray, J., Trask, B., van den Engh, G., Fuscoe, J. and VAN DEKKEN, H, 1986. Cytogenetic analysis by in situ hybridization with fluorescently labeled nucleic acid probes. Cold Spring Harbor Symp. Quant. Biol. 51: 151-157

Plohl, M. and UGARKOVIĆ, $Đ$. 1994a. Characterization of two abundant satellite DNAs from the mealworm Tenebrio obscurus. - J. Mol. Evol. 39: 489-495

PLOHL, M. and UGARKović, Đ. 1994b. Analysis of divergence of Alphitobius diaperinus satellite DNA - roles of recombination, replication slippage and gene conversion.-Mol. Gen. Genet. 242: $297-304$

Plohl, M., Borštnik, B., Lucijanić-Justić, V. and UGARKOVIĆ, Đ. 1992. Evidence for random distribution of sequence variants in Tenebrio molitor satellite DNA. - Genet. Res. 60: 7-13

Plohl, M., Lucijanić-Justić, V., Ugarković, D., PetitPIERRE, E. and JuAN, C. 1993. Satellite DNA and heterochromatin of the flour beetle Tribolium confusum. - Genome 36 : 467-475

Pons, J., Petitpierre, E. and Juan, C. 1993. Characterization of the heterochromatin of the darkling beetle Misolampus goudoti: cloning of two satellite DNA families and digestion of chromosomes with restriction enzymes. - Hereditas 119: 179185

SúmNer, A.T. 1972. A simple technique for demonstrating centromeric heterochromatin. - Exp. Cell Res. 75: 304-306

SumNer, A. T. 1990. Banding with fluorochromes other than quinacrine. - In: Chromosome banding, (ed. U. HymaN), Unwin Hyman, London, p. 163-165

Ugarković, D., Plohl, M. and Gamulin, V. 1989. Sequence variability of satellite DNA from the mealworm Tenebrio molitor. - Gene 83: 181-183

Ugarković, Đ., Plohl, M., Petitpierre, E., Lucijanić-JusTIC, V. and JuAN, C. 1994. Tenebrio obscurus satellite DNA is resistant to cleavage by restriction endonucleases in situ. Chromosome Res. 2: 217-223

Valgeirsdottir, K., 'Traverse, K. L. and Pardue, M. 1990. HeT DNA: A family of mosaic repeated sequences specific for heterochromatin in Drosophila melanogaster.-Proc. Natl. Acad. Sci. USA 87: 7998-8002

Warburton, P. E. and Willard, H. F. 1990. Genomic analysis of sequence variation in tandemly repeated DNA. Evidence for localized homogeneous sequence domains within arrays of $\alpha$-satellite DNA. - J. Mol. Biol. 216: 3-16

WEITH, A. 1985. The fine structure of euchromatin and centromeric heterochromatin in Tenebrio molitor chromosomes. Chromosoma 91: 287-296 